\title{
Technology Acceptance Model for Mobile Health Systems
}

\author{
Marwan El-Wajeeh ${ }^{1}$, Prof. Galal H. Galal-Edeen ${ }^{2}$, Dr. Hoda Mokhtar ${ }^{3}$ \\ 1, 2, 3 (Department of Information Systems, Faculty of Computers and Information / Cairo University \\ , Egypt)
}

\begin{abstract}
The purpose of this paper is to explore the factors that influence health-related consumer's acceptance to use the mobile technology as a tool for receiving healthcare services. Based on technology acceptance model (TAM), this paper provides a better understanding of antecedent of key acceptance constructs (e.g. intention to use, perceived usefulness, perceived ease of use). The proposed research model and hypotheses validated and tested with data collected from 302 Egyptians and Yemenis patients, health professionals, and general health users. The results are analyzed using a number of statistical techniques including partial least squares. The key findings obtaining from the results of the three surveyed stakeholders reveal that: (1) ninety percent are indented to use mobile health services. (2) While intention to use has greatly influenced by perceived usefulness, the impact of perceived ease of use varies. (3) Perceived value, perceived ease of use and portability factors are significantly affect perceived usefulness. (4) Self-efficacy and technology anxiety have a great impact on perceived ease of use. (5) The impact of the rest of the suggested factors ranged from medium, low, and insignificant. The research made an in-depth exploration and examination of the factors that influence user's intention to use mobile health services focusing on technological, cultural, organizational, political, and social aspects whereas most of the previous studies considered only one or two aspects together. The proposed model can be applied to assess mobile health user's acceptance, thereby help mobile health developers and providers to develop better mobile health applications that meet the needs of the potential users.
\end{abstract}

Keywords: Intention to use, Mobile health, portability, Resistance to change, Technology anxiety, Technology acceptance model

\section{Introduction}

With the rapid growth of mobile technology, mobile health technologies are considered a feasible solution in order to monitor the status of patients in an easy and innovative way; it has created the potential to transforming healthcare delivery in more accessible, affordable, and effective form [1]. Compared to the traditional electronic health (e-health) which may heavily rely on computers and wired internet connections, mobile health can leverage the advantages of wireless cellular communication capability (e.g., mobility) and other key features such as portability and long-life battery power allow health services to be delivered with fewer temporal and spatial constraints [2]. Because the mobility, portability, and flexibility of mobile technologies, mobile health services greatly improve the accessibility of healthcare. Moreover, mobile health services can save lot of time and cost; it will motivate people to develop good habits, and may reshape their style of obtaining health services [3]. Mobile health has emerged as an important part of the field of e-health. It is more than a communications channel; it refers to the delivery, facilitation, and management of health-related information and services via mobile tools including cell phones, tablets, sensors, monitors, and wireless infrastructure in general. Mobile healthcare technologies include a wide range of healthcare applications and services including mobile telemedicine, patient monitoring, location-based medical services, and pervasive access to healthcare information, providing great benefits to both patients and physicians. This advancement of information technology led to the current healthcare systems being transformed from traditional scenarios that requires manual care to more advanced scenarios where patients can be automatically be monitored and fast emergency provided [4].

Besides the potential economic and medical gains of mobile health services, the acceptance and adoption of the use of mobile health applications facing challenges and barriers at the cultural, technological, social, organizational and political levels, especially in developing countries [5]. According to our interviews with patients, health professionals and health-related organizations there are several critical barriers. First, one of the main observations that we noticed is the lack of the knowledge about mobile health applications and services and its benefits. Second, there are concerns with respect to ease of use, data privacy, and the negative consequence introduced by m-health user's wrong operations. Third, some health professionals and patients do not want to change the routine of providing healthcare services, despite the potential benefits of mobile health. Many patients feel that doctors are very busy and do not have time to use the mobile to follow up and remotely monitor them. Fourth, there is a big challenge with respect to the trust, more than one patient do not trust any government system. one of the employees working in a health organization told us "a company has provided team health medical call center services, but unfortunately when the patient called the call center for medical 
consultation he/she wait for a long period of time without being connected to a doctor", thus we need to define laws that regulate this process. Finally, it is difficult to adopt mobile health services unless there is social acceptance and official support. the adoption of mobile health services is not merely dependent on proposed technology's capabilities the adoption is however, mostly depend on health professionals, patients, and care givers willingness to incur the new technology and it also depends on to the extent the government and relatedhealth organizations will provide the necessary support. It is important to remember, "Not the software but the human side of implementation cycle ... Will block the progress in seeing that the delivered systems are used effectively" [6]. Mobile health is a new technology. Thus, before putting it to use it is necessary to know whether this technology is acceptable or not and to what extent the related-health consumers are intending to use mobile health services. The development of m-health services needs a process of users' acceptance, so research on factors that affect users' adoption seems important and urgent. A major research question is: what would be the main factors driving people to use or not to use mobile health services? This question is of utmost importance in today's context where there is an emphasis on trying to educate people to use health promotion interventions in order to improve health and reduce cost. Focus on consumers or 'acceptors' [7] of healthcare services is critical since their perceptions will ultimately determine the success or failure of any such initiative. As mobile health is an emerging technology, the assessment studies on this type of technology is still rare, few studies have investigated technology acceptance of mobile devices in healthcare. Among the limited literature on mobile health technology acceptance, most of the previous studies considered only one or two aspects together. For example, [8] and [9] only research on technical perspective based on Delone and Mclean IS success model. Authors in [10], [11] and [12] addressed the psychology aspect (e.g., resistance to change and technology anxiety). [13], [14], [6] and [3] focus on positive aspects of technology acceptance, paying less attention to the factors and negative impressions that may affect the acceptance of technology. Most previous studies on the acceptance of $\mathrm{m}$-health are seen from healthcare professionals perspective as summarized by [6]. For instance, authors in [1] assessed m-health acceptance and sustainability from healthcare professionals' point of view using Task Technology Fit (TTF) model. This study aims to assess and provide an understanding of the factors that influence mobile health intention to use from patients, health professionals, and general users' perspectives, focusing on technological, cultural, organizational, political, and social aspects.

Out of all the acceptance models, Technology Acceptance Model (TAM) is a well-established, widely used, and highly accepted model for predicting user acceptance of technology [15]. Although the TAM has been suggested as suitable model to explore the critical determinants that affect users' intention to use a new technology in various technology fields, many researchers indicate that traditional acceptance models need to be extended and modified when applied to mobile technology [16]. We argue that more factors should be considered to explain intention related to use mobile devices in healthcare context. In this paper TAM was extended to include additional variables such as: social influence, facilitating conditions, perceived value, technology anxiety, trust, data privacy, resistance to change, self-efficacy and technology characteristics that influence a decision maker intention to adopt mobile health technology.

The rest of the paper is organized as follows: section 2 focuses on the literature review and surveyed the existing assessment models. Section 3 comes up with a theoretical foundations and research model based on existing theory. Research methodology and results are introduced in section 4. Next, the discussion of the study results is reported. Lastly, we present the conclusions and future work.

\section{Existing Mobile Health Assessment Frameworks}

Before the establishment of a theoretical ground for the proposed research, a detailed literature survey was undertaken to analyze the state of the art of $\mathrm{m}$-health assessment models. Mobile health is an emerging technology, thus the assessment studies on these type of technology is still rare, few studies have investigated technology acceptance of mobile in healthcare in general. Out of the limited studies on m-health, there are different research gaps. First, most of the studies considered only one or two aspects together. For example, [8] and [9] only research on technical perspective based on Delone and Mclean IS success model [10]. Also the authors in [11] and [12] addressed the psychology aspect (e.g., resistance to change and technology anxiety). Second, most previous studies in health care acceptance focused on the perspective of healthcare professionals rather than focusing on the patients' point of view [6]. Authors in [1] assessed m-health acceptance and sustainability from healthcare professionals' point of view using task Technology Fit (TTF) model. Third, prior studies of [13], [14], [6], [3] and [17] addressed positive aspects of technology acceptance, paying less attention to the factors that may negatively affect the acceptance of technology. Finally, according to our knowledge and research, no previous assessment model addresses the political and managerial barriers that inhibit mobile health services acceptance [1]. However, the review of mobile health assessment studies indicates that there is a complexity to establish a comprehensive $\mathrm{m}$-health assessment due to the various $\mathrm{m}$-health stakeholders with differing needs. This study attempts to assess and provide an understanding of mobile health from patients, 
health professionals, and general users' perspectives, focusing on technological, cultural, organizational, political, and human side aspects.

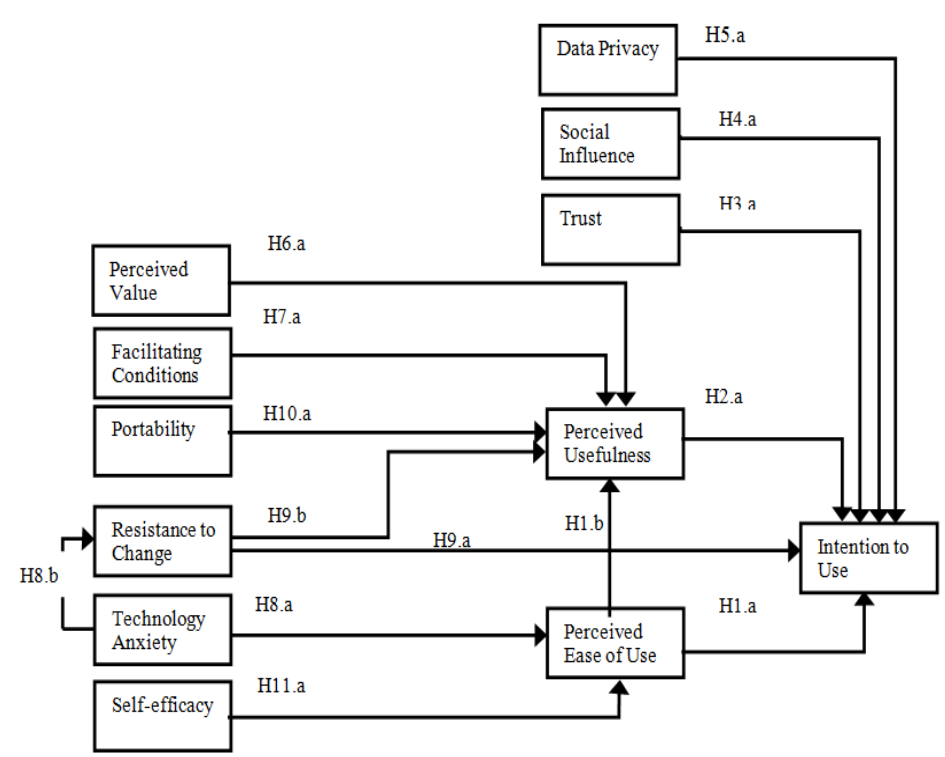

Figure 1: Proposed mobile health assessment model

\section{Proposed Framework and Hypotheses}

Various theoretical models have emerged to explore and explain factors that cause individuals to accept/reject or continue the use of new technology. such theories is the Technology Acceptance Model (TAM) which developed by [18]. TAM is a model for predicting user acceptance of technology based upon estimating the three core constructs, which are perceived usefulness, perceived ease of use and intention to use. For the reasons mentioned in introduction section, the TAM was extended to include additional variables.

As shown from the proposed model in Fig.1, we assumed several hypotheses. First, we hypothesized that intention to use is affected by perceived ease of use, perceived usefulness, trust, social influence, data privacy, and resistance to change (H1.a, H2.a, H3.a, H4.a, H5.a, and H9.a) respectively. Second, we hypothesized that perceived usefulness is influenced by perceived ease of use, perceived value, facilitating conditions, resistance to change, and portability (H1.b, H6.a, H7.a, H9.b, H10.a) respectively. Third, perceived ease of use is affected by two factors: technology anxiety and self-efficacy (H8.a, H11.a). Finally, we hypothesized that resistance to change is affected by technology anxiety (H8.b). Below we will discuss in depth the factors that we proposed to have effect on intention to use mobile health services, thereby lead to accept mobile health technology.

\section{1) Perceived ease of use}

Perceived ease of use has been identified as one of the major factors that motivate individuals to accept and use specific technology [19]. Whereas the complexity and difficulty of IT products will affect the ease of use, then this difficulty may be caused by many factors such as information technology literacy, less experience, and lack of training and personal skills. When the users perceive that the system will ease of use and can help them to complete their work better, the users will have the desire of using this system.

According to the technology acceptance model (TAM) there are a relationships between perceived ease to use, perceived usefulness and intention to use [19] and [15]. In the context of health services this associations were supported by [17] and [11]. Thus, we propose:

H1.a: Perceived ease of use is positively associated with intention to use mobile health services.

H1.b: Perceived ease of use is positively associated Perceived usefulness

\section{2) Perceived usefulness}

Several studies have found that perceived usefulness is a primary and utmost the primary predictor of information technology usage [16], [3], [14] and [19]. In the context of mobile health, we can define the perceived usefulness as the degree to which a person feels that using mobile devices for healthcare services will be advantages to her/him. Thus, if the health professionals or patients believe that $\mathrm{m}$-health systems are useful and it will enhance their job performance, increase their productivity, improve the quality of patient's life and making them more convenient, then this usefulness will directly lead to the intention to use and actual usage. 
Doctors believe that a lack of information, awareness, and responsibility among patients increase the amount and severity of diseases. If they had access to a patients' previous health information, it could save them a lot of time and they would be able to help their patients more efficiently. Based on above, we hypothesize:

H2.a: Perceived usefulness is positively associated with intention to use mobile health services.

\section{3) Trust in mobile health services and services providers}

Trust is a social and personal factor studied in various dimensions such as personality-based trust, knowledge-based trust and so on. In the context of acceptance the authors in [20] assumed that "the past experiences have the biggest impact on the current level of trust", This is what is known as the knowledge-based trust. Authors in [16] found that trust has a direct significant effect on m-commerce users' intention to deploy m-commerce technology. Also authors in [14] indicated that the trust has big influence on sample population intention to use e-health and m-health services. Increasing an individual's trust lead to the in an individual's intention to use mobile health services. In developing countries, several patients they do not trust health services especially those offered by the government. Thus, we argue that:

H3.a: Trusts is associated with intention to use mobile health services

\section{4) Social influence}

Social influence is defined as change in an individual's thoughts, feelings, attitudes, or behaviors that results from interaction with another individual or group [15]. Some of related mobile healthcare consumers may have less familiar with a new technology, hence the people such as family or friends who are important to a patient can influence on his/her opinions to pushing him/her to use mobile for healthier lifestyle. The direct compliance effect of society on intention to use will have positive indicators when the individuals perceive that a social actor wants from them to use mobile for healthcare. If health organizations or government starts to use or support using mobile technology to provide e-health services this behavior will affect the doctors, health staff and patients to use mobile health, therefore consist a social awareness and obtaining health services will be a popular phenomenon. People readiness to receive mobile health services are affected by the perspective of other people. Several researches [3] and [13] found that the social influence have a directly affect intention to use. Therefore, we assume that:

H4.a: Social influence has a positive effect on intention to use mobile health services.

\section{5) Data privacy}

There is no doubt that security and privacy protection of cross-institutional electronic patient records is a very crucial, especially in the healthcare information sharing. Information privacy is the most essential technical aspect in medical field [21]. The importance of security and privacy concerns in an online environment have been broadly discussed and reported in several studies. [22] reported that privacy and security concerns were found to be a major barrier to the internet shopping. These concerns have been extended to the electronic health. While technology itself may resolve some security concerns through encryption and other control mechanisms, privacy issues are too critical to be left to technological resolutions alone. Using mobile devices in healthcare are raising concerns about privacy, data security, and loss of control. Sensitive and detailed information is available everywhere and anytime. As a conclusion of the above discussion, we propose:

H5.a: Data privacy has a positive effect intention to use mobile health services.

\section{6) Perceived value}

The main aim for accepting mobile health services includes not only improving healthy performance, but also acquiring enjoyment and social approval. Perceived value refers to the user's evaluation of the service or product after comparing the profit and the cost, it is the balance between perceived benefits and cost and it is consider the overall assessment of services utility [23]. Mobile health technology can offer large benefits to all countries, lead to economic growth and promise a better life for individuals. Several studies show that the emotional value, quality value, price value and social value consider the main parts of perceived value [23], [13] and [24]. Emotional value expresses the pleasure and an enjoyment when user accepts mobile health services, social value reflects social approval and acceptance. Quality value defines the expected quality of the services, such as reliable and fast connection response, and effective help. Cost value reflects some concerns when adopting mobile health service. Consumers are usually sensitive to the price when service price exceeds their expectation [23]. Based on discussion above, we propose:

H6.a: Perceived value has a positive effect on perceived usefulness

\section{7) Facilitating conditions}

Facilitating conditions are defined as "the degree to which an individual believes that an organizational and technical infrastructure exist to support the use of the system" [25]. This includes perceived managerial and 
organizational support, and the availability of technical infrastructure resources. Analytical and examination study to explore the policy barriers [5] that affect existing m-health applications shown that $m$-health solutions need to national health priorities, ICT rights and regulations, medical advices liability, access to health information, personal ID, and developing policies for use these solutions. Missing regulations is seen as one of the major barriers for the m-health market to enter the next market phase. [26] stated several conditions to be fulfilled before implementing m-health or e-health applications including the global and national policies that support the use of mobile for health and infrastructure implementation aspects. Prior researches such [15] found a significant relationship between facilitating conditions and perceived usefulness, Therefore, we propose:

H7.a: Facilitating conditions have a positive effect on perceived usefulness.

\section{8) Technology anxiety}

The anxiety of community toward using mobile technology for delivering healthcare considers one of the most important reasons that inhibit the m-health technology adoption [9]. It has a negative effect on the quality of care that the m-health provider can provide for the patients. [27] defined mobile healthcare anxiety as "a high anxious response towards interaction with the mobile patient safety information system." Prior studies [28] and [11] indicate that there are a negative relationship between technology anxiety and perceived ease of use. Many users especially elderly worried about; using mobile devices for delivering healthcare services, unexpected errors caused by m-health systems, making mistakes they cannot correct. In the context of mobile health, high technology anxiety can be featured because it regard to human health. Technology anxiety may play important role in shaping health-related users perception of ease of use. Technology Anxiety also can lead to increasing the resistance to change. Previous study on technology acceptance has established this linkage between technology anxiety and the resistance to change [11]. Thus, we argue:

H8.a: Technology anxiety has a negative effect on ease of use mobile health services.

H8.b: Technology anxiety is positively associated with resistance to change.

\section{9) Resistance to change}

Cultural aspect in handling technology or communicating ease of use can lead to problems during the development stage if they are not considered proactively. Introducing a new technology often involves some form of change for users who would like to keep their routines and do not like any activity that can change their life style [11]. Therefore, the resistance to change plays an important role in the adoption a new technology. Whenever the resistance to change is low, the user will give relatively high evaluation on usefulness and there will be a positive impression towards intention to use and vice versa. Resistance to change is related to people's behavior under conditions of change in a variety of contexts. While some people would like to keep their routines and do not like any activities that can change their obtaining/delivering health services even the expected benefits, some people are more inclined to try to adopt a new technology. We expect that $m$-health services will face a part of resistance from both health professionals and patients. Several patients told us that the doctors might have no time to follow up them remotely. In addition, several patients usually want to be faceto-face with doctors. [29], [12] and [11] concluded resistance to change represent a major barrier for mobile health technology acceptance. A significant impact for resistance to change on the perceived usefulness and intention to use is found. As a conclusion of above discussion, we propose:

H9.a: Resistance to change is negatively associated with intention to use mobile health services.

H9.b: Resistance to change is negatively associated with perceived usefulness.

\section{0) Portability}

Because the mobility, portability, ubiquity and flexibility of mobile technologies, mobile health services greatly improve the accessibility of healthcare. Compared with traditional e-health that uses personal computers and laptop devices, mobile health can take advantages of its strengths to provide healthy, timely, convenient, and personalized information to meet e-health services needs of patients and health professionals. The small size, low weight and rechargeable feature of mobile technologies make them appropriate for delivering health services with fewer temporal and spatial constraint [2]. Portability is an important factor that will positively affects the acceptance of using mobile-health services [9] making them more suitable for patients and health workers, since they can be taken anywhere and used any time. Several studies shown that the portability feature will improve the effectiveness of delivering healthcare services and increase the use of healthcare [2], [11] and [9]. Therefore, we assume that:

H10.a: portability has a positive effect on perceived usefulness.

\section{1) Mobile health self-efficacy}

mobile health self-efficacy refers to "the degree of one's conviction and confidence in his or herself ability to perform mobile related task successfully for the usage of mobile devices" [30]. Self-efficacy does not 
means individual's actual skills, it is represent the individual's judgment in own capability that he or she can perform specific action. The more he/she believes in his/her ability, the less effort he/she would expect. Ones' faith in its ability to browse the internet, download and use mobile health applications, and send messages increase the ease of use these applications [28], [15] and [29] shown that an individual self-efficacy will influence person's behavior to use mobile technological applications. This study will investigate a mobile selfefficacy as a factor that decides personal behavior change.

H11.a: Self-efficacy has a positive effect on the ease of use mobile health services.

\subsection{Constructs and Items Used}

\section{Methodology and Results}

The issue of cultural context is an important; a questionnaire is reliable in one setting does not mean it can then be used reliably elsewhere, even if the questionnaire has been previously tested [31]. Thus, in order to test the proposed model and ensure the content validity of the scales, the measures for constructs were mainly adapted from prior studies with words changed to the research context. Three stakeholders (Patients, Health Professionals, and General Users) tested the proposed model with three questionnaires contained the same constructs but they have some changes in their construction (items used) as appropriate for each stakeholder. The measure for intention to use construct was adapted from [18] and [15].The measures of perceived usefulness and perceived ease to use are adapted from [18], [11] and [17]. Items that measure the technology anxiety construct were adapted from [25] and [11]. The measure for resistance to change was adapted from [29]. The measure for perceived value was adapted from [23] and [13]. The measure for facilitating conditions was adapted from [25] [13]. The measure for social influence was adapted from [25]. the measure for portability construct was adapted from [32]. The measure for trust construct was adapted from [20]. The measure for the privacy construct was adapted from [6]. Measure of the self-efficacy was adapted from [33]. The questionnaire items that were directed to patient's stakeholder are shown in appendix A. Five-point Likert scale was used ranging from "strongly disagree" (1) to "strongly agree" (5) in which participants were asked to indicate an appropriate response. As the survey was conducted in Egypt, the questionnaires was translated to the Arabic language, and because of the limited knowledge among health professionals, and patients of the health-related uses of mobile devices, we introduced a brochure to explain the concept of mobile health services with some examples about the applications of mobile health for non-communicable diseases.

\subsection{Data Collection}

Data were gathered with a survey questionnaire, containing questions focusing on demographics and scales measuring the variables in the proposed model. The samples for the research were collected through questionnaires administered in a field survey in Egypt at hospitals (e.g. Kasr El-Ainy), medical institutes, private clinics, as well as we put the questionnaire regarding health professionals online on the internet at specific websites belong to the doctors.

Table 1 Demographic Samples Profile

\begin{tabular}{|l|l|c|c|c|}
\hline \multicolumn{2}{|l|}{ stakeholders } & P (\%) & HP (\%) & G (\%) \\
\hline Gender & Male & 57.4 & 64.6 & 52.1 \\
& Female & 42.6 & 35.4 & 47.9 \\
\hline Age & $18-30$ & 21.8 & 31.5 & 59.2 \\
& $31-40$ & 25.7 & 57.7 & 39.4 \\
& $41-50$ & 19.8 & 5.4 & 1.4 \\
& $>50$ & 28.7 & 1.5 & 0 \\
& Missing & 4 & 5 & 0 \\
\hline Resident Area & Urban & 76.6 & 94.6 & 83.1 \\
& Rural & 21.8 & 5.4 & 16.9 \\
\hline Nationality & Egyptian & 59.4 & 53.1 & 38.0 \\
& Yemen & 39.6 & 40.0 & 59.2 \\
& Others & 1 & 6.9 & 2.8 \\
\hline Qualification & Below of diploma & 9.9 & 0 & 0 \\
& Diploma \& high school & 31.6 & 13.8 & 14.1 \\
& Bachelor & 39.6 & 36.9 & 60.6 \\
& Master or above & 10.8 & 47.7 & 23.9 \\
& Missing & 6 & 0 & 1.4 \\
\hline Job & Nursing & & 20.8 & \\
& Cardiologist & & 17.0 & \\
& Oncologist & & 18.5 & \\
& General practitioner & & 21.5 & \\
& Others & 22.2 & \\
\hline
\end{tabular}

$(\mathrm{P}=$ Patients, $\mathrm{HP}=$ Health professionals, $\mathrm{G}=$ General users $)$ 
Among 459 distributed questionnaires, we obtained 302 valid questionnaires (101 for patients, 130 for health professionals and 71 for general users). Table 1 illustrates respondent demographic.

The descriptive statistics for each construct items are shown in Table 2. All means where greater than 3.0 , ranging from 3.0 to 4.3 except resistance to change construct has mean value equal 2.1 and technology anxiety in general user's stakeholder. This indicates overall positive responses to the constructs that are measured in the study. The low mean value of resistance to change due to the assumption that resistance to change has negative influence on the intention to use and perceived usefulness. Thus, the mean value of the resistance to change construct is in its natural context. The standard deviations for all variables were less than one, indicating a narrow dispersion of item scores around the mean scores.

Table 2 Descriptive Statistics of Constructs

\begin{tabular}{|l|l|l|l|l|l|l|}
\hline \multirow{2}{*}{ Stakeholder } & \multicolumn{2}{c|}{ Patients } & \multicolumn{2}{c|}{ HP } & \multicolumn{2}{c|}{ G } \\
\cline { 2 - 7 } Construct & mean & SD & M. & SD & M & SD \\
\hline Intention to Use & 4.2 & .63 & 4.3 & .74 & 4.28 & .57 \\
\hline Perceived Usefulness & 4.3 & .68 & 4.2 & .65 & 4.34 & .48 \\
\hline Perceived Ease to Use & 4.0 & .65 & 3.9 & .73 & 4.17 & .59 \\
\hline Trust & 3.5 & .88 & 3.6 & .83 & 3.94 & .78 \\
\hline Social Influence & 4.0 & .78 & 4.0 & .66 & 4.36 & .49 \\
\hline Data Privacy & 3.0 & .81 & 3.4 & .63 & 4.15 & .73 \\
\hline Perceived Value & 4.0 & .60 & 3.9 & .79 & 3.99 & .57 \\
\hline Facilitating Conditions & 3.9 & .68 & 3.5 & .68 & 3.76 & .65 \\
\hline Technology Anxiety & 3.1 & .98 & 3.3 & .98 & 3.92 & .96 \\
\hline Resistance to Change & 2.1 & .80 & 2.1 & .60 & 4.15 & .53 \\
\hline Portability & 4.1 & .62 & 4.0 & .63 & 4.27 & .51 \\
\hline Self-efficacy & 3.9 & .69 & 4.1 & .71 & 4.33 & .54 \\
\hline
\end{tabular}

\subsection{Measurement Model Assessment}

Our research model was tested using the Partial Least Squares (PLS) technique. PLS has been widely adopted in IS research. It is suitable for validating predictive models that uses reflective latent constructs, it places minimal demands on sample sizes and data distribution assumptions [34]. It can estimate the loadings and weights of items on constructs and the casual relationships among constructs in multistage models. PLS supports two measurement models: 1) the assessment of the measurement model and 2) the assessment of the structural model. In order to ensure the appropriateness of the measurement model, we assessed the reliability and two types of validity (i.e., convergent validity and discriminant validity).

\subsubsection{Indicators and constructs reliability}

Reliability of constructs can be measured by Cronbach's alpha (CA) estimates, the composite reliability (CR), and AVE (average variance extracted) [35] and [36].

Cronbach's alpha is the basic statistic for determining the reliability of measure based on the internal consistency and with a lower threshold of 0.70 [36]. Composite reliability assesses whether items are sufficient in representing their respective construct and a common lower threshold is 0.70 [36], [35]. Another reliability measure, Average variance extracted, which reflects the overall amount of variance captured by the constructs in relation to the mount of variance attributable to measurement error. The AVE is a more conservative measure than composite reliability and their suggested acceptable level is 0.50 or above for a construct. The first one to check is "indicator reliability" or "items reliability" which equals the square of the loading value. When we calculated the square of leading for each indicator of patients-based respondents, we have seen that, three indicators out of forty are not reliable and all of the remaining indicators have individual indicator reliability values that are larger than the preferred level of 0.7 .

Regarding results that have been obtained from health professionals-based measurement model, four indicators out of forty are not reliable. Two problematic items (PV3, PV7) are found in the construct "Perceived Value", one item (FC1) in the construct "Facilitating Conditions". In addition, one item (RTC2) in the construct "Resistance to Change". It should also be noted that data privacy construct has been removed because health professional respondents dispersed between approval and disapproval and there is no stability of a particular opinion, the measurement construct did not reach the cat-off threshold of reliability and validity. As for the general users' stakeholder, four indicators out of thirty-nine are not reliable. Two problematic items are found in the construct "Perceived Value", one problematic items in the construct "Facilitating Conditions", and one problematic item was found in the construct "Data Privacy". 
Table 3 Patients-based Summary Results for Reflective Outer Models.

\begin{tabular}{|c|c|c|c|c|c|}
\hline Construct & Items & Loading & $\mathbf{C A}$ & CR & AVE \\
\hline ITU & $\begin{array}{l}\text { ITU1 } \\
\text { ITU2 }\end{array}$ & $\begin{array}{l}0.90 \\
0.85\end{array}$ & 0.71 & 0.87 & 0.77 \\
\hline $\mathbf{P U}$ & $\begin{array}{l}\text { PU1 } \\
\text { PU2 }\end{array}$ & $\begin{array}{l}0.91 \\
0.87\end{array}$ & 0.73 & 0.88 & 0.79 \\
\hline PETU & $\begin{array}{l}\text { PETU1 } \\
\text { PETU2 } \\
\text { PETU3 }\end{array}$ & $\begin{array}{l}0.82 \\
0.88 \\
0.79\end{array}$ & 0.77 & 0.87 & 0.69 \\
\hline PV & $\begin{array}{l}\text { PV1 } \\
\text { PV2 } \\
\text { PV3 } \\
\text { PV5 } \\
\text { PV6 } \\
\text { PV8 }\end{array}$ & $\begin{array}{l}0.72 \\
0.84 \\
0.83 \\
0.85 \\
0.71 \\
0.72 \\
\end{array}$ & 0.87 & 0.90 & 0.62 \\
\hline $\mathbf{T}$ & $\begin{array}{l}\mathrm{T} 1 \\
\mathrm{~T} 2\end{array}$ & $\begin{array}{l}0.88 \\
0.88\end{array}$ & 0.72 & 0.88 & 0.78 \\
\hline SI & $\begin{array}{l}\text { SI1 } \\
\text { SI2 }\end{array}$ & $\begin{array}{l}0.91 \\
0.85\end{array}$ & 0.72 & 0.88 & 0.78 \\
\hline DP & $\begin{array}{l}\text { DP1 } \\
\text { DP2 }\end{array}$ & $\begin{array}{l}0.93 \\
0.81\end{array}$ & 0.70 & 0.87 & 0.77 \\
\hline FC & $\begin{array}{l}\text { FC1 } \\
\text { FC2 } \\
\text { FC3 } \\
\text { FC4 } \\
\text { FC5 }\end{array}$ & $\begin{array}{c}0.7 \\
0.74 \\
0.77 \\
0.75 \\
0.73\end{array}$ & 0.80 & 0.86 & 0.55 \\
\hline TA & $\begin{array}{l}\text { TA1 } \\
\text { TA2 } \\
\text { TA3 }\end{array}$ & $\begin{array}{l}0.75 \\
0.85 \\
0.80\end{array}$ & 0.72 & 0.84 & 0.64 \\
\hline RTC & $\begin{array}{l}\text { RTC1 } \\
\text { RTC2 } \\
\text { RTC3 }\end{array}$ & $\begin{array}{c}0.77 \\
0.72 \\
0.9\end{array}$ & 0.72 & 0.83 & 0.62 \\
\hline $\mathbf{P}$ & $\begin{array}{l}\text { P1 } \\
\text { P2 } \\
\text { P3 } \\
\text { P4 }\end{array}$ & $\begin{array}{c}0.7 \\
0.83 \\
0.9 \\
0.78 \\
\end{array}$ & 0.82 & 0.88 & 0.65 \\
\hline SE & $\begin{array}{l}\text { SE1 } \\
\text { SE2 } \\
\text { SE3 }\end{array}$ & $\begin{array}{c}0.84 \\
0.83 \\
0.9\end{array}$ & 0.82 & 0.89 & 0.74 \\
\hline
\end{tabular}

1.3.2 Convergent and discriminant validity

Convergent validity is assured if factor loadings are 0.7 or above and if each item loads significantly on its latent construct. Discriminant validity is assured when the following two conditions are met: a) the value of the AVE is above the threshold value of 0.50 , and b) the square root of the AVE is larger than all other cross correlations. From Table 4 it is found that all of the AVE values are greater than the acceptable threshold of 0.5 , so convergent validity is confirmed. [35] suggest that the square root of AVE in each construct can be used to establish discriminant validity, if this value is larger than other correlation values among the constructs. Thus, the measurement model was considered satisfactory with the evidence of adequate reliability, convergent validity, discriminant validity and was employed for hypothesis testing and research model validation. Table 4 shows the discriminant validity.

Table 4 Patients-Based Discriminant Validity

\begin{tabular}{|l|l|c|c|c|c|c|c|c|c|c|c|c|}
\hline & ITU & PU & PETU & PV & T & SI & FC & TA & RTC & P & SE & DP \\
\hline ITU & $\mathbf{0 . 8 8}$ & & & & & & & & & & & \\
\hline PU & 0.68 & $\mathbf{0 . 8 9}$ & & & & & & & & & & \\
\hline PETU & 0.63 & 0.64 & $\mathbf{0 . 8 3}$ & & & & & & & & & \\
\hline PV & 0.57 & 0.65 & 0.62 & $\mathbf{0 . 7 8}$ & & & & & & & & \\
\hline T & 0.27 & 0.14 & 0.24 & 0.25 & $\mathbf{0 . 8 8}$ & & & & & & & \\
\hline SI & 0.43 & 0.25 & 0.45 & 0.42 & 0.27 & $\mathbf{0 . 8 8}$ & & & & & & \\
\hline FC & 0.40 & 0.40 & 0.46 & 0.63 & -0.04 & 0.31 & $\mathbf{0 . 7 4}$ & & & & & \\
\hline TA & -.34 & -0.41 & -0.40 & -0.37 & -0.12 & -0.15 & -0.42 & $\mathbf{0 . 8 0}$ & & & & \\
\hline RTC & -.35 & -0.53 & -0.37 & -0.42 & -0.10 & -0.18 & -0.41 & 0.42 & $\mathbf{0 . 7 9}$ & & & \\
\hline P & 0.49 & 0.6 & 0.60 & 0.59 & 0.12 & 0.42 & 0.54 & -0.37 & -0.42 & $\mathbf{0 . 8 1}$ & & \\
\hline SE & 0.42 & -0.30 & 0.54 & 0.40 & 0.48 & 0.39 & 0.19 & -0.16 & -0.13 & 0.40 & $\mathbf{0 . 8 6}$ & \\
\hline DP & -0.1 & 0.00 & 0.09 & 0.05 & 0.25 & 0.01 & -0.08 & -0.13 & 0.01 & 0.05 & 0.21 & $\mathbf{0 . 8 8}$ \\
\hline
\end{tabular}




\subsection{Structural Model Assessment}

The structural model presents information about the path significance and the squared R (R2) gives an indication of the model's predictive power. In this section, we will show in detail the structural model assessment regarding patients, and we brief the part regarding health professionals and general users. The PLS results for the patients-based structural model is illustrated in Fig. 2 and the t-values and path coefficients values are shown in Table 5. The coefficient of determination R2 is 0.597 for the "intention to use" construct. This means that the six constructs (PETU, PU, T, SI, DP, and RTC) moderately explain 59.7\% of the variance in intention to use. Perceived value, facilitating conditions, resistance to change, portability, and perceived ease of use explain $58.1 \%$ of the variance of perceived usefulness. Technology anxiety and self-efficacy together explain $39.2 \%$ of the variance of perceived ease to use. Finally, the technology anxiety explains $23.7 \%$ of the variance of resistance to change. Regarding path coefficient the results show that the relationships between perceived ease of use and intention to use $(\beta=0.231, \mathrm{t}=3.129)$ (H1.a) is significant, perceived ease of use is significantly impact perceived usefulness $(\beta=0.275, \mathrm{t}=3.713)$ in support of H1.b, also perceived usefulness has significantly influence intention to use ( $\beta=0.456$, t0 4.259) in support of H2.a. Perceived value is found to be associated and has significant influence on perceived usefulness $(\beta=0.308, \mathrm{t}=3.571)$ leading support H3.a.

Trust in mobile health services and services providers have significantly affect intention to use ( $\beta=0.150, \mathrm{t}=2.126)$ leading support H4.a. Social influence is found to be positively associated with intention to use $(\beta=0.175, \mathrm{t}=2.316)$ in support of H5.a. Privacy is found to be positively associated with intention to $(\beta=0.175, \mathrm{t}=2812)$. Thus, H6.a is supported. Facilitating conditions found to be negatively associated with perceived usefulness $(\beta=0 .-149, \mathrm{t}=2.078)$ support H7.a.

In addition, the technology/ m-health anxiety has high significant impact on perceived ease of use ( $\beta=-$ $0.319, \mathrm{t}=5.142$ ) leading support H8.a which proposed that there are negative association between technology anxiety and perceived ease of use, the results show that high positive significant impact of technology anxiety on resistance to change with $(\beta=0.487, t=8.200)$ leading support H8.b. The results also suggest that resistance to change has a significant effects on perceived usefulness $(\beta=-0.231, \mathrm{t}=2.923)$ but there is insignificant effects on intention to use $(\beta=-0.016, \mathrm{t}=0.0891)$. Thus, the H9.a is supported while H9.b is not. Portability and perceived usefulness ( $\beta=0.205, \mathrm{t}=2.330)$ is significant. Thus, H10.a is supported. Also the mobile self-efficacy and ease of use $(\beta=0.492, \mathrm{t}=6.840)$. Thus, H11.a is supported. Regarding health professionals, all hypotheses are supported except H1.a and H3.a. As well as data privacy construct did not satisfy the reliability and validity conditions. As for the general users, all hypotheses are supported except H1.a, H7.a, and H9.b.

Table 5 Results for the Structural Model

\begin{tabular}{|l|c|l|l|l|l|}
\hline Hypothesized path & SD & Beta & t-values & $\mathbf{P}$-value & Result \\
\hline $\mathrm{PETU} \rightarrow \mathrm{ITU}$ & 0.07 & 0.231 & 3.129 & $\mathrm{P}<0.002$ & Supported \\
\hline $\mathrm{PETU} \rightarrow \mathrm{PU}$ & 0.08 & 0.275 & 3.713 & $\mathrm{P}<0.001$ & Supported \\
\hline $\mathrm{PU} \rightarrow \mathrm{ITU}$ & 0.11 & 0.456 & 4.259 & $\mathrm{P}<0.001$ & Supported \\
\hline $\mathrm{PV} \rightarrow \mathrm{PU}$ & 0.09 & 0.308 & 3.571 & $\mathrm{P}<0.001$ & Supported \\
\hline $\mathrm{T} \rightarrow \mathrm{ITU}$ & 0.06 & 0.150 & 2.126 & $\mathrm{P}<0.05$ & Supported \\
\hline $\mathrm{SI} \rightarrow \mathrm{ITU}$ & 0.07 & 0.175 & 2.316 & $\mathrm{P}<0.05$ & Supported \\
\hline $\mathrm{DP} \rightarrow \mathrm{ITU}$ & 0.07 & -0.175 & 2.812 & $\mathrm{P}<0.01$ & Supported \\
\hline $\mathrm{FC} \rightarrow$ PU & 0.07 & -0.149 & 1.878 & $\mathrm{P}<0.05$ & Supported \\
\hline $\mathrm{TA} \rightarrow$ PETU & 0.06 & -0.319 & 5.142 & $\mathrm{P}<0.001$ & Supported \\
\hline $\mathrm{TA} \rightarrow \mathrm{RTC}$ & 0.07 & 0.487 & 8.200 & $\mathrm{P}<0.001$ & Supported \\
\hline $\mathrm{RTC} \rightarrow$ PU & 0.08 & -0.231 & 2.923 & $\mathrm{P}<0.01$ & Supported \\
\hline $\mathrm{RTC} \rightarrow$ ITU & 0.05 & 0.016 & 0.143 & $\mathrm{p}>\mathbf{0 . 1}$ & Not supported \\
\hline $\mathrm{P} \rightarrow \mathrm{PU}$ & 0.08 & 0.226 & 2.330 & $\mathrm{P}<0.05$ & Supported \\
\hline $\mathrm{SE} \rightarrow$ PETU & 0.07 & 0.492 & 6.840 & $\mathrm{P}<0.001$ & Supported \\
\hline
\end{tabular}




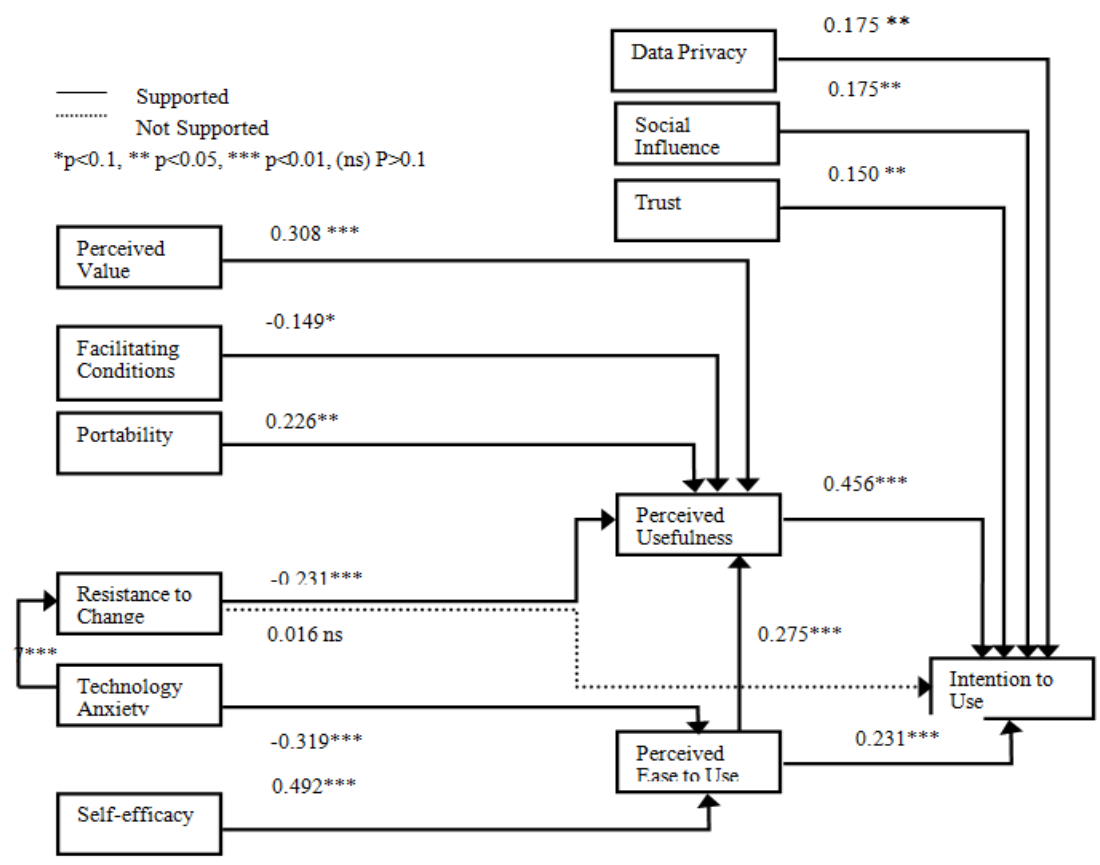

Figure 2 The SmartPLS 2.0 results for the hypothesized paths (Patients-based).

\section{Discussion}

This study examined the factors that influence mobile health user's intention to use from patients, health professionals, and general users' perspectives. The proposed model was introduced based on technology acceptance model with extensions for: trust, social influence, data privacy, perceived value, facilitating conditions, technology anxiety, resistance to change, portability, and self-efficacy. The overall acceptance of using $\mathrm{m}$-health services is great, that there are $90 \%$ of the people surveyed intend to use mobile health applications whereas $6.5 \%$ did not intend to, and 3\% have neutral opinions. From the results of the three surveyed stakeholders, we found that the perceived usefulness has great impact and significantly affects intention to use mobile health applications whereas the impact of perceived ease of use varies. Perceived value, perceived ease of use and portability have great impact and significantly affect perceived usefulness. Selfefficacy and technology anxiety significantly affect perceived ease of use. Social influence has significantly affect intention to use. The impact of the rest of the suggested factors differed from high, medium, and insignificant according to each one of stakeholders' data that used to assess the proposed model.

Resistance to change has a strong negative impact and significantly affects intention to use when we tested the model using health professionals and general users' data while it has insignificant affect when we tested it using patients' data. Resistance to change also has a significant effect on perceived usefulness when we tested the model using patients and health professionals' data but it has insignificant effects when we tested the model by general users' data.

Data privacy has insignificant effects on intention to use when we examined the proposed model by health professionals and general users' data, but it has a significant effect when we examined it using patients' data. However, the impact of trust constructs was a significant impact on intention to use when we tested the model with patients and general user's data; the impact was not significant when we tested it using health professionals' data. Perceived ease of use has insignificant effect on intention to use when tested by health professionals and general users. Finally, it was expected to be a positive relationship between facilitating conditions and perceived usefulness but form the results we found that facilitating conditions have negative effect on perceived usefulness when tested by patients and health professionals and have insignificant effect when tested using general users' data. This may be due to the difference in the viewpoints of the stakeholders with respect to facilitating conditions (e.g. establishing legislation, determining liability, providing needed technical support, and supporting $\mathrm{m}$-health initiative) that expected to be available from relevant healthcare organizations. applications.

The main limitation of our study is that stakeholders surveyed did not actually use mobile health 


\section{Conclusion and Future Work}

As m-health is more and more seen as a mandatory technology that will contribute to improving the healthcare services delivery in developing countries, it is necessary to understand the factors that affect relatedhealth consumers to accept or reject mobile health services.

This paper presented a model for m-health applications acceptance based on TAM and made an expansion of technology acceptance in a mobile health field, the presented model incorporated cultural, social, technological, political, and organizational aspects. The outcomes from this study reveal that the technology acceptance model with extension constructs could be applied to assess the health-consumers behavior intention to use a mobile technology for e-health services. In terms of contributions to practice, the outcomes of our study can provide some recommendations and insights to mobile health providers and developers. The providers can pay more attention to the driving factors that affect user acceptance. To develop a better mobile health services, the developer should note that usefulness, ease of use, technology anxiety, resistance to change, portability, selfefficacy, perceived value, facilitating conditioning, social influence, data privacy, and trust are important determinants for m-health application acceptance. From the technical aspect, Mobile devices as compared to desktop computers have limitations in processing, storage capacity, and power consumption that hinder them from functioning in a more or less acceptable capability and reliability. These limitations must be acknowledged when developing mobile health applications. Therefore, future research should focus on these issues and how can be addressed.

\section{References}

[1] A. Tariq, S. Akter, AN ASSESSMENT OF M-HEALTH IN DEVELOPING COUNTRIES USING TASK TECHNOLOGY FIT MODEL, Proceedings of the S eventeenth Americas Conference on Information Systems, Detroit, Michigan, 2011.

[2] C. Free, G. Phillips, L. Watson, L. Galli, L. Felix, P. Edwards, V. Patel, A. Haines, The Effectiveness of Mobile-Health Technologies to Improve Health Care Service Delivery Processes: A Systematic Review and Meta-Analysis., PLoS Med 10(1): e1001363. doi:10.1371/journal.pmed.1001363 (2013).

[3] X.-t. Guo, J.-q. Yuan, X.-f. Cao, X.-d. Chen, Understanding the acceptance of mobile health services: A service participants analysis, Management Science and Engineering (ICMSE), 2012 International Conference on, 2012, pp. 1868-1873.

[4] C. Yunzhi, h. Lu, L. Xinhui, Application of ubiquitous multimedia in Mobile Electronic Patient Record, Ubi-media Computing (UMedia), 2010 3rd IEEE International Conference on, IEEE, 2010, pp. 207-210.

[5] Patricia Mechae, Hima Batavia, Nadi Kaonga, Sarah Searle, Ada Kwan, Adina Goldberger, Lin Fu , James Ossman, Barriers and Gaps Affecting mHealth in Low and Middle Income Countries: A Policy White Paper, mHealth Alliance, Washington, D.C, 2010.

[6] M. Cocosila, N. Archer, Adoption of mobile ICT for health promotion: an empirical investigation, Electronic Markets Vol. 20, issue (3-4) (2010) pp 241-250.

[7] V. Mantzana, Themistocleous, M., Irani, Z., \& Vincenzo, M., Identifying healthcare actors involved in the adoption of information systems., European Journal of Information Systems Vol.16(1) (2007) PP. 190-102.

[8] S. Chatterjeea, S. Chakrabortyb, S. Sarker, F.Y. Laud, Examining the success factors for mobile work in healthcare: a deductive study, Decision Support Systems Vol. 46 (2009) pp. 620-633.

[9] P. Keikhosrokian, N. Zakaria, N. Mustaffa, A. Kianpisheh, P. Limtrairut, M.I. Sarwar, A proposal to measure success factors for location-based mobile cardiac telemedicine system (LMCTS), International Journal of Smart Home Vol. 6, no. 3 (2012) pp. 57-66.

[10] W.H. DeLone, E.R. McLean, The DeLone and McLean Model of Information Systems Success: A Ten-Year Update, Journal of Management Information Systems Vol.19 (2003) pp.9-30

[11] X. Guo, Y. Sun, N. Wang, Z. Peng, Z. Yan, The dark side of elderly acceptance of preventive mobile health services in China, Electronic Markets Vol.23 (2013) pp. 49-61.

[12] A. Bhattacherjee, N. Hikmet, Physicians' Resistance toward Healthcare Information technologies: A Dual-Factor Model, Proceedings of the 40th Hawaii International Conference on System Sciences, IEEE, Washington, DC, USA, 2007, pp. pp1 41.

[13] W. Boontarig, W. Chutimaskul, V. Chongsuphajaisiddhi, B. Papasratorn, Factors influencing the Thai elderly intention to use smartphone for e-Health services, Humanities, Science and Engineering Research (SHUSER), 2012 IEEE Symposium on, 2012, pp. 479-483.

[14] A.H.H.M. Mohamed, H. Tawfik, D. Al-Jumeily, L. Norton, MoHTAM: A Technology Acceptance Model for Mobile Health Applications, Developments in E-systems Engineering (DeSE), 2011, IEEE, 2011, pp. 13-18.

[15] V. Venkatesh, H. Bala, Technology Acceptance Model 3 and a Research Agenda on Interventions, Decision Sciences Vol. 39 (2008) pp. 273-315.

[16] S.G. Yaseen, S. Zayed, Exploring determinants in deploying mobile commerce technology: Amman stock exchange, Information Society (i-Society), 2010 International Conference on, IEEE, 2010, pp. 612-620.

[17] P. Yu, H. Li, M.P. Gagnonc, Health IT acceptance factors in long-term care facilities: A cross-sectional survey, international journal of medical informatics Vol. 78 (2009) pp. 219-229.

[18] F.D. Davis, R.P. Bagozzi, P.R. Warshaw, User acceptance of computer technology: a comparison of two theoretical models, Management science Vol. 35 (1989) pp. 982-1003.

[19] F.D. Davis, Perceived Usefulness, Perceived Ease of Use, and User Acceptance of Information Technology, Management Information Systems Research Center Vol. 13 (1989) pp. 319-340.

[20] S. Von Watzdorf, T. Ippisch, A. Skorna, F. Thiesse, The Influence of Provider Trust on the Acceptance of Mobile Applications: An Empirical Analysis of Two Mobile Emergency Applications, Mobile Business and 2010 Ninth Global Mobility Roundtable (ICMBGMR), 2010 Ninth International Conference on, 2010, pp. 329-336.

[21] R. Luanrattana, Considerable factors of incorporating PDAs to medical education, Information Technology Based Higher Education and Training (ITHET), 2011 International Conference on, 2011, pp. 1-8.

[22] U.J. Godwin, Privacy and security concerns as major barriers for e-commerce: a survey study, Information Management \& Computer Security Vol. 9 (2001) PP. 165-174.

[23] Z. Tao, The Impact of Perceived Value on User Acceptance of Mobile Commerce, Electronic Commerce and Security, 2008 International Symposium on, IEEE, 2008, pp. 237-240. 
[24] W. Ruijin, T. Pan, Y. Cao, Users' acceptance behavior for m-commerce based on customer perceived value and TAM, E -Business and E -Government (ICEE), 2011 International Conference on, IEEE, 2011, pp. 1-4.

[25] V. Venkatesh, M.G. Morris, G.B. Davis, F.D. Davis, User Acceptance of Information Technology: Toward a Unified View, MIS Quarterly Vol. 27 (2003) pp. 425-478.

[26] m-Health alliance, Strategic Priorities Retrieved from http://www.mhealthalliance.org/our-work/strategy, 2003.

[27] W.-Y. Jen, C.-C. Chao, Measuring mobile patient safety information system success: An empirical study, International Journal of Medical Informatics Vol. 77 (2008) pp. 689-697.

[28] V. Venkatesh, F.D. Davis, A Theoretical Extension of the Technology Acceptance Model: Four Longitudinal Field Studies, Management Science Vol. 46 (2000) pp. 186-204.

[29] O. Nov, C. Ye, Users' personality and perceived ease of use of digital libraries: the case for resistance to change, Journal of the American Society for Information Science and Technology vol. 59, no.5 (2008) pp. 845-851.

[30] R. Sungyul, K. Hyojin, J. Soohyun, An Empirical Study on Mobile Web Browsing Service Adoption in Korea, Mobile Business, 2009. ICMB 2009. Eighth International Conference on, 2009, pp. 324-328.

[31] E.A. Tuleja, L. Beamer, C. Shum, E.K.Y. Chan, Designing and Developing Questionnaires for Translation Tutorial, Professional Communication, IEEE Transactions on 54 (2011) 392-405.

[32] T. Chun-Wang, L. Chun-Hsiung, Investigating the antecedents of intentions to purchase a netbook as a second laptop, Education and Management Technology (ICEMT), 2010 International Conference on, 2010, pp. 285-291.

[33] L. Ching-Chang, H. Ming-Chia, The Influence of Mobile Self-Efficacy on Attitude towards Mobile Advertising, New Trends in Information and Service Science, 2009. NISS '09. International Conference on, 2009, pp. 1231-1236.

[34] W.W. Chin, (Ed.), The partial least squares approach for structural equation modeling, Lawrence Erlbaum Associates., in G. A. Marcoulides (Ed.), Modern methods for business research (PP. 195-236). London, 1998.

[35] C. Fornell, F.L. Bookstein, Two structural equation models:lisrel and pls applied to consumer exit-voice theory, Journal of Marketing Research Vol. 19, No. 4 (1981) pp. 440-452.

[36] J.F. Hair, R.L. Tatham, R.E. Anderson, W. Black, (Eds.), Multivariate data analysis (5th ed.). Prentice-Hall: Upper Saddle River., 1998.

\section{APPENDIX A: Questionnaire Items for Patients Stakeholder Intention to Use:}

ITU1. Assuming I had access to MHNCDs applications, I intend to use them.

ITU2. I have no objection of using healthcare applications via mobile if available.

\section{Perceived usefulness:}

PU1. I expect that using MHNCDs applications will give me the necessary medical information.

PU2. I think that if I use MHNCDs applications, it could save me a lot of time.

\section{Perceived Ease to Use:}

PETU1. I think that using mobile healthcare applications will be easy learned.

PETU2. I expect that my interaction with mobile health services will be clear and understandable.

PETU3. I expect that interacting with MHNCDs applications will not require a lot of mental effort.

\section{Perceived Value:}

PV1. I expect that using MHNCDs applications will be helpful for obtaining good health services.

PV2. I expect that using MHNCDs will improve the patient's life quality/ my quality life.

PV3. I expect that the internet connection to MHNCDs applications will be fast and reliable.

PV4. I expect that MHNCDs services will have acceptable standard of quality.

PV5. I would feel comfort when using MHNCDs services.

PV6. I expect that using mobile devices for healthcare will make good impression on my patient's side.

PV7. I would be concerned about how match I would pay if I subscribe to mobile health services.

PV8. I expect that using MHNCDs will give it social approval.

Trust:

T1. I expect that the agencies which provide mobile health applications will provide trustful services

T2. Based on my experience with healthcare providers I know they are trustworthy.

\section{Social Influence:}

SI1. If related people to me think that I should use the MHNCDs applications for obtaining healthcare services I will use them.

SI2. If related health professionals to me think that I should use the MHNCDs applications for obtaining healthcare services I will use them.

\section{Data Privacy:}

DP1. I fear that using mobile devices to deliver healthcare services will cause me to lose control over data privacy

DP2. I trust that MHNCDs services providers do not share my personal information with others.

DP3. I fear that internet hackers (criminals) might take control of my information if I use MHNCDs 


\section{Facilitating Conditions:}

FC1. Resources necessary (e.g. internet and network coverage) to use MHNCDs are available.

FC2. I expect that the government will give priority to support mobile health initiatives.

FC3. I expect that the government will define the necessary legislations and laws that regulate providing mobile health services.

FC4. I expect that non-government health organizations such as "World Health Organization" will support mobile health initiatives.

FC5. I expect that technical support will be available for assistance with any difficulties in MHNCDs systems usage.

\section{Technology Anxiety:}

TA1. I feel worried about using mobile devices for delivering healthcare services.

TA2. I feel worried about unexpected errors that be caused by MHNCDs systems

TA3. I hesitate to use technology for fear of making mistakes I cannot correct

\section{Resistance to change:}

RTC1. I consider that using mobile devices to deliver healthcare services a negative idea.

RTC2. I don't want MHNCDs to make any change in my routine healthcare providing lifestyle.

RTC3. Although the potential benefits of MHNCDs services, I do not want to use them.

\section{Portability:}

P1. I think that using NCDs healthcare applications on mobile devices will be convenient way to access health information on the go.

P2. I expect that using NCDs healthcare applications on mobile devices will be suitable to communicate with patients and physicians on the go.

P3. I think that providing NCDs healthcare services on mobile devices will be suitable way when I am outside hospital or outpatient clinic.

P4. Mobile devices allow me to share needed health information with relevant people on the go.

\section{Self-efficacy:}

SE1. I feel I am able to use mobile web page search engines (such as Google) to search for mobile health applications and download them.

SE2. I feel confident I will be able to use healthcare applications through mobile phones to access health information, as well as sending email and graphic images.

SE3. I feel I will be able to use the mobile internet to send and receive email and attach files with MHNCDs applications interfaces. 